\title{
Quadro clínico e tratamento da dermatite da área das fraldas - Parte II
}

\author{
Clinical presentation and treatment of diaper dermatitis - Part II
}

\author{
Juliana Dumet Fernandes ${ }^{1}$ \\ Maria Cecília Rivitti Machado² \\ Zilda Najjar Prado de Oliveira ${ }^{3}$
}

\begin{abstract}
Resumo: A dermatite da área da fralda irritativa primária é a mais prevalente desse tipo, sendo provavelmente a afecção cutânea mais freqüente na primeira infância. Constitui fonte significativa de desconforto para a criança. $\mathrm{O}$ uso da fralda ocasiona aumento da temperatura e da umidade locais. Há conseqüente maceração da pele, que se torna mais susceptível à irritação ocasionada pelo contato prolongado da urina e das fezes. Freqüentemente surge infecção secundária por Candida albicans ou por bactérias como Bacillos faecallis, Proteus, Pseudomonas, Staphylococcus e Streptococcus. O uso de pós, óleos, sabões e pomadas irritantes agravam o quadro clínico. A melhor conduta é a prevenção que engloba um conjunto de medidas que têm como objetivos manter a superficie seca, limitar a mistura e dispersão da urina e das fezes, reduzir seu contato com a pele, evitar irritação e maceração, preservar a função de barreira cutânea e manter, sempre que possível, um pH ácido. O tratamento médico consiste em medidas simples, ajustadas de acordo com a gravidade e o tipo de dermatite.

Palavras-chave: Candida albicans; Dermatite das fraldas; Dermatite das fraldas/terapia
\end{abstract}

\begin{abstract}
Diaper irritant contact dermatitis is the most prevalent diaper dermatitis and, probably, the most common cause of cutaneous disease in infants. Wearing diapers causes over hydration and increase of local temperature and humidity. As a consequence, the skin becomes susceptible to friction from movement under the diaper. Occlusion, maceration and possibly Candida and bacteria may all play a role. Oils, soaps and powders can be irritant and aggravate the eruption. The best thing to do is prevention. Treatment is simple and depends on dermatitis type and severity.Keywords : HTLV-I infections; HTLV-I infections/complications; Human T-lymphotropic virus 1; Lymphoma, T-cell, cutaneous; Paraparesis, tropical spastic; Skin; Skin manifestations
\end{abstract}

Keywords: Candida; Diaper dermatitis; Diaper dermatitis/treatment

\section{INTRODUÇÃO}

Como já abordado na parte I, publicada em número anterior, a expressão dermatite da área das fraldas abrange um conjunto de dermatoses inflamatórias que atingem a região do corpo coberta pela fralda: períneo, nádegas, abdômen inferior e coxas. Incluem-se na dermatite da área das fraldas as doenças causadas diretamente pelo uso da fralda, como dermatite irritativa primária da área das fraldas (que, para alguns autores, seria sinônimo de dermatite da área da fralda) e a dermatite de contato alérgica ao material plástico da fralda (muito rara); as dermatites exacerbadas pelo uso da fralda (como psoríase, dermatite atópica, dermatite seborréica, miliária, candidose, dermatite de contato alérgica); e aquelas que ocorrem nessa localização, mas que não estão relacionadas com seu uso (acrodermatite enteropática, histiocitose de células de Langerhans, granuloma glúteo infantil, dermatite estreptocócica perianal, impetigo bolhoso, escabiose, sífilis congênita, Aids). Assim, a dermatite da área das fraldas deve ser interpretada não apenas como uma entidade diagnóstica específica, mas

Aprovado pelo Conselho Editorial e aceito para publicação em 05.01 .09

* Trabalho realizado no Hospital das Clínicas da Faculdade de Medicina da Universidade de São Paulo (USP) - São Paulo (SP), Brasil.

Conflito de interesse: Nenhum / Conflict of interest: None

Suporte financeiro: Nenhum / Financial funding: None

Médica colaboradora do Departamento de Dermatologia do Hospital das Clínicas da Faculdade de Medicina da Universidade de São Paulo (USP) - São Paulo (SP), Brasil. Médica supervisora do Departamento de Dermatologia da Faculdade de Medicina da Universidade de São Paulo (USP) - São Paulo (SP), Brasil.

Médica diretora do Departamento de Dermatologia do Hospital das Clínicas da Faculdade de Medicina da Universidade de São Paulo (USP) - São Paulo (SP), Brasil.

(C)2009 by Anais Brasileiros de Dermatologia 
como um diagnóstico de localização, que engloba um amplo grupo de dermatoses e resulta da interação de múltiplos fatores.

A dermatite da área da fralda irritativa primária é a mais prevalente. ${ }^{1}$ Trata-se de dermatite de contato por irritante primário na área da fralda. $\mathrm{O}$ aumento da temperatura e da umidade local provoca maceração da pele, que se torna mais susceptível à irritação ocasionada pelo contato prolongado com urina e fezes. O uso de pós, óleos, sabões e pomadas irritantes agravam o quadro clínico. Além disso, é freqüente o aparecimento de infecção secundária por Candida albicans ou por bactérias como Bacillos faecallis, Proteus, Pseudomonas, Staphylococcus e Streptococcus.

Sabe-se que a susceptibilidade das crianças atópicas e com dermatite seborréica é bem maior, e a concomitância com outras entidades pode dificultar o diagnóstico diferencial. ${ }^{2-5}$ Além disso, os fatores genéticos envolvidos ainda não estão completamente esclarecidos ou firmados.

Não existe predileção por sexo, raça ou padrão social. ${ }^{6}$ Indivíduos de outras faixas etárias podem também desenvolver a doença em situações especiais associadas à incontinência urinária e fecal. ${ }^{7} \mathrm{O}$ quadro clínico é semelhante, com as mesmas complicações, e igual terapêutica é utillizada.

Nos últimos tempos, observou-se diminuição da freqüência e gravidade da dermatite da área das fraldas, principalmente devido à melhoria na qualidade do material utilizado em sua confecção, o que contribuiu sobremaneira para o avanço nos cuidados de higiene.

\section{QUADRO CLÍNICO, DIAGNÓSTICO E EXAMES COMPLEMENTARES}

\section{Dermatite da área das fraldas irritativa primária}

Caracteriza-se por apresentar lesão eritematosa confluente, brilhante, que varia de intensidade ao longo do tempo. Pode manifestar-se através de pápulas eritematosas associadas a edema e leve descamação. Atinge, tipicamente, as regióes de maior contato com a fralda e é caracteristicamente conhecida como "dermatite em W". As pregas são, geralmente, poupadas, e os locais mais acometidos são superfícies convexas das nádegas, coxas, parte inferior do abdômen, púbis, grandes lábios e escroto (Figura 1). A candidose é considerada a principal complicação da dermatite, e, quando ocorre simultaneamente, o eritema se intensifica e surgem lesões papulopustulosas satélites. ${ }^{8}$ Quando o eritema começa a melhorar, a pele torna-se enrugada, com aspecto apergaminhado. Em crianças com menos de quatro meses de idade, a primeira manifestação pode ser um ligeiro eritema perianal.

A intensidade das alterações cutâneas da dermatite da área da fralda varia de leve a grave. A alteração do $\mathrm{pH}$ da pele pode desencadear o desenvolvimento de infecções oportunistas de origem bacteriana, fúngica ou

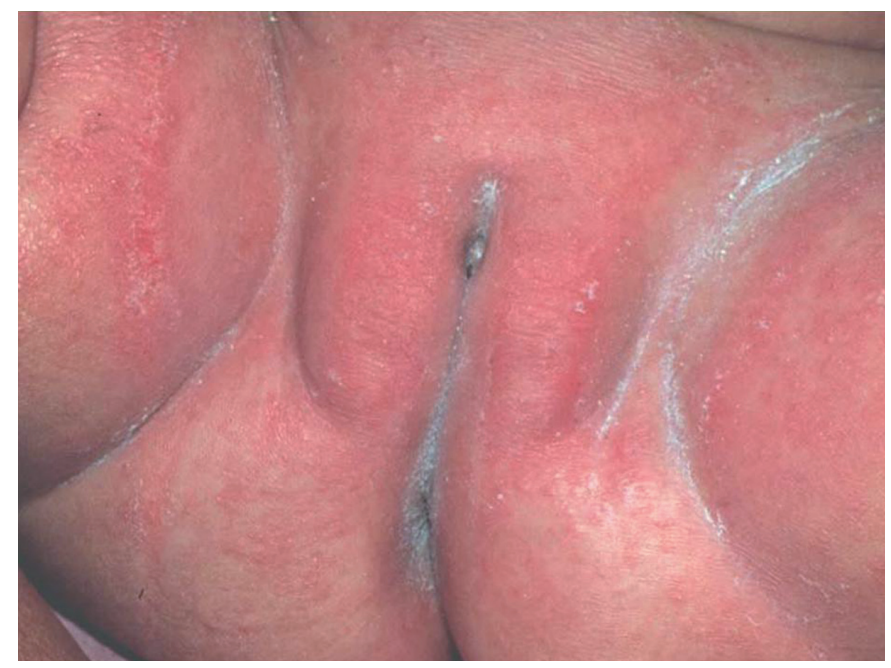

Figura 1: Dermatite da área das fraldas irritativa primária. Lesões eritêmato-descamativas, edematosas na região da fralda, poupando pregas

viral. Nos casos mais graves, a erupção pode atingir áreas não cobertas pela fralda. Se não houver tratamento, ou se infeccionar, pode evoluir para maceração e exsudação, formação de pápulas, vesículas ou bolhas, erosão ou ulceração da pele, infecção do pênis, vulva ou do trato urinário. Além disso, pode até mesmo ocorrer sinéquias ou cicatrização dos órgãos genitais. Quando associado com síndrome diarréica, o quadro freqüentemente tem rápida evolução e é mais intenso.'

Existem dois subtipos menos freqüentes de dermatite da área da fralda irritativa primária. Um deles, mais conhecido por dermatite de Jacquet, pseudo-sifílide de Jacquet ou eritema papuloerosivo sifilóide, é forma incomum e grave de dermatite da área da fralda que se desenvolve pela persistência e intensidade do agente agressor, associação de fatores agravantes (irritantes tópicos, fungos) e/ou por manejo inadequado. ${ }^{1,10,11}$ Caracteriza-se por pápulas firmes e salientes, de coloração vermelho-escura ou violácea, que sucedem fase vésico-erosivo-ulcerativa, e suas ulcerações são ovais ou redondas, com fundo raso e de configuração crateriforme (Figura 2). Acomete, principalmente, nádegas, coxas superiores e, eventualmente, panturrilhas. ${ }^{12,10}$ Ao regredir, esse tipo de dermatite pode resultar em atrofia e hiperpigmentação. Geralmente, acomete crianças com mais de seis meses de idade. Entretanto, a variante de Jacquet já foi descrita também em adultos. ${ }^{13}$ Nos meninos, as úlceras podem ocorrer na glande e meato urinário, levando a desconforto e disúria. ${ }^{14} \mathrm{O}$ outro subtipo, também conhecido por "dermatite das marés", caracteriza-se por eritema em faixa, confinado apenas às margens da fralda na área do abdômen e das coxas. Esse tipo de dermatite resulta da fricção constante que ocorre na borda da fralda, agravada por ciclos consecutivos de umidade e secagem. 


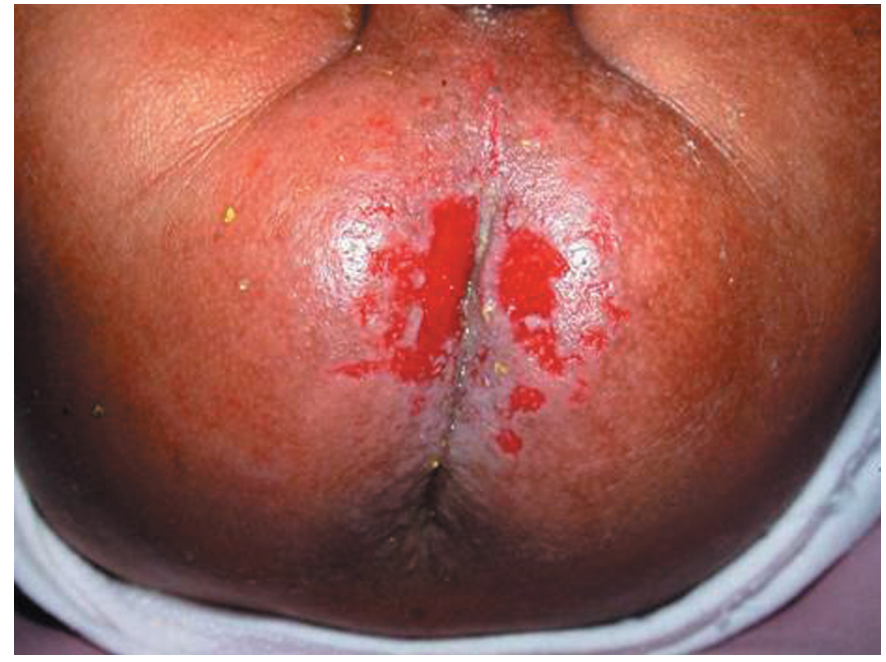

FiguRA 2: Dermatite de Jacquet. Lesões vésico-erosivo-ulcerativas, com ulcerações ovais de fundo raso e de configuração crateriforme, na região das nádegas

O diagnóstico da DFIP é clínico e deve-se realizar exame micológico direto para a pesquisa de contaminação por Candida quando o eritema se intensificar, houver pústulas satélites ou ocorrer resolução lenta do quadro.

\section{Outras causas de dermatite na área das fraldas}

\subsection{Candidose}

$\mathrm{O}$ ambiente úmido e quente produzido pela fralda favorece a proliferação da C.albicans, que pode penetrar o estrato córneo, ativar a via alternada do complemento e induzir um processo inflamatório. ${ }^{4} \mathrm{~A}$ candidose na área das fraldas é cada vez mais comum nas crianças. Isso, provavelmente, se deve ao uso mais freqüente de antibióticos orais de largo espectro, com subseqüente diarréia. Clinicamente, apresenta-se como placas eritematosas que se podem estender à genitália, associadas a descamação periférica e pústulas satélites eritematosas. Pode também apresentar pequenas pápulas rosadas encimadas por escamas, coalescentes em algumas áreas (Figura 3). As regiões perineal anterior, perianal e dobras estão habitualmente envolvidas, e isso ajuda a diferenciar a candidose da DFIP. Na cronificação ou recorrência freqüente do quadro, é importante pesquisar infecção por cândida no aparelho digestivo (examinar a cavidade oral), vaginite por cândida ou mastite materna. O diagnóstico é clínico e laboratorial através do exame micológico direto da lesão, evidenciando pseudo-hifas (o material deve ser colhido na periferia do eritema, na pápula ou na pústula periférica) (Quadro 1).

\subsection{Dermatite de contato alérgica}

A verdadeira alergia de contato às fraldas pode complicar outro tipo de dermatite preexistente ou surgir isoladamente. Caracteriza-se por eritema e descamação leves, e, eventualmente, vesículas e pápulas. É incomum em crianças com menos de dois anos de idade. Deve-se suspeitar desse quadro quando não se obtém resposta a tratamentos adequados. Embora seja pouco habitual, pode ocorrer após contato da pele com determinados alérgenos, tais como parabenos, lanolina, compostos mercuriais e neomicina ou, ainda, certas substâncias presentes em fraldas descartáveis (como, por exemplo, borrachas), detergentes ou preparações de aplicação tópica. O diagnóstico é clínico e pode ser confirmado através de testes de contato (Quadro 1).

\subsection{Dermatite atópica}

Apesar de haver maior suscetibilidade dos atópicos a agentes irritantes, a dermatite atópica caracteristicamente poupa, na maioria dos casos, a área da fralda. Quando atinge essa região, manifesta-se como a dermatite irritante primária. Tende, contudo, a ser crônica e relativamente resistente ao tratamento. Podem-se observar exsudação e crostas secundárias à infecção por Staphilococcus aureus, bem como, devido ao prurido crônico, escoriações e liquenificação. Deve-se salientar, entretanto, que os sinais indiretos de prurido, escoriações, por exemplo, não se manifestam antes dos dois anos de idade. O diagnóstico é clínico (Quadro 1).

\subsection{Dermatite seborréica}

É doença inflamatória crônica que acomete com muita freqüência a região da fralda. Seu início ocorre, em geral, entre três e 12 semanas de vida e, raramente, após os seis meses de idade. Clinicamente, são placas eritematosas com escamas graxentas nas áreas intertriginosas. Embora atinja preferencialmente as pregas, não apresenta lesões satélites, ao contrário da candidose. O diagnóstico é clínico e, geralmente, ocorre resolução espontânea por volta dos três aos seis meses de idade (Quadro 1).

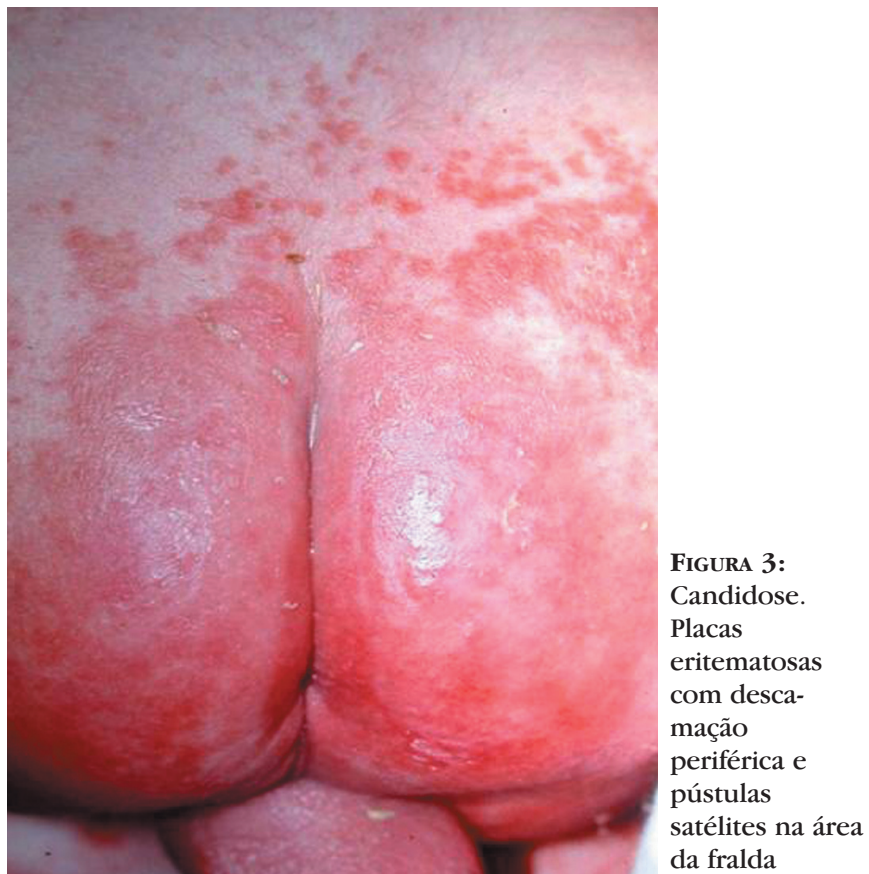




\subsection{Psoríase}

Doença rara em crianças, mas, quando surge no primeiro ano de vida, costuma iniciar-se na área da fralda. Esse fato deve-se, provavelmente, ao fenômeno de Koebner, isto é, reprodução em área traumatizada da lesão secundária ao uso da fralda. Entretanto, em grande parte dos casos, não se restringe à área das fraldas, estendendo-se caracteristicamente para as regiões peri e umbilical. Clinicamente, apresenta-se com lesões bem delimitadas, com escamas espessas e micáceas. O diagnóstico é clínico. Devem-se pesquisar lesões típicas de psoríase em outras localizações habituais da doença, como, por exemplo, cotovelos, joelhos, face e couro cabeludo (Quadro 1).

\subsection{Acrodermatite enteropática}

É doença rara, de herança autossômica recessiva, que ocorre devido à deficiência de zinco sérico. Começa, em geral, no lactente alimentado com leite de vaca desde o nascimento ou, nos demais, quando da substituição do leite materno por leite de vaca. Suspeita-se dessa diagnose quando ocorre dermatite persistente e de apresentação atípica na área da fralda. A tríade clássica consiste de dermatite de localização acral e periorificial, alopecia e diarréia.

A dermatite acral inicia-se lentamente com placas eritêmato-descamativas, bem delimitadas, eczematosas, na face, couro cabeludo e áreas anogenitais, podendo acometer pregas inguinais, região periocular, perinasal, perioral e extremidades distais. As lesões progridem, e desenvolvem-se placas vesicobolhosas, com múltiplas erosões e pústulas. Se a evolução for crônica, podem surgir liquenificação ou placas psoriasiformes. O diagnóstico é feito pela demonstração de baixos níveis de zinco plasmático ou sérico. A dosagem diminuída de fosfatase alcalina também auxilia no diagnóstico, pois se trata de metaloenzima dependente de zinco (Quadro 1).

\subsection{Sífilis congênita}

As lesões na sífilis congênita podem estar presentes desde o nascimento ou nos três primeiros meses de vida. Podem-se manifestar, na região anogenital, como máculas, pápulas, bolhas, lesões úmidas, semelhantes a verrugas (condiloma plano) associadas a erosões. Pode também ocorrer erupção como a da sífilis secundária com eritema, pápulas e escamas. Em muitos casos aparecem lesões em palmas e plantas. Devido ao aumento da incidência da sífilis, sua forma congênita deve ser incluída nos diagnósticos diferenciais da dermatite da área da fralda. O diagnóstico é clínico e laboratorial através de exames sorológicos (VDRL/TPHA ou FTAAbs) e, de acordo com o contexto, exames liquóricos e radiológicos (Quadro 1).

\subsection{Histiocitose de células de Langerhans (doença de Letterer-Siwe)}

A histiocitose de células de Langerhans é doença rara e até fatal que pode acometer a área da fralda. Surge, geralmente, nos primeiros anos de vida, mas também pode desenvolver-se em crianças com mais de três anos de idade. Deve ser considerada na presença de dermatite com aspecto inicial semelhante ao da dermatite seborréica de difícil tratamento. Apresenta-se, clinicamente, como pápulas eritêmato-acastanhadas ou purpúricas, podendo ter lesões hemorrágicas ou ulceradas. Para o diagnóstico, faz-se necessária a biópsia cutânea, com estudo histopatológico e imuno-histoquímico (Quadro 1).

\subsection{Granuloma glúteo infantil}

É dermatose nodular rara de etiologia desconhecida, embora possa surgir após tratamento tópico com corticosteróides potentes. Pode, também, representar resposta cutânea localizada a processo inflamatório prolongado, ocorrendo em área de dermatite irritativa primária preexistente ou mesmo após sua resolução. Não existem evidências da relação entre a gravidade da dermatite da área da fralda e a incidência dessa erupção. Acredita-se que a participação da Candida albicans esteja envolvida na patogenia da doença. Caracteriza-se clinicamente por um ou vários nódulos ovais, eritêmato-purpúricos nas superfícies convexas da pele, poupando as flexuras. O diagnóstico é clínico e histopatológico. Pode ocorrer resolução espontânea de algumas lesões (Quadro 1).

\subsection{Abuso sexual}

Suspeita-se nos casos de condiloma acuminado ou condiloma plano, em crianças de qualquer idade. Devido a suas implicações legais, o diagnóstico deve ser abordado com cautela.

\subsection{Impetigo bolhoso}

O ambiente úmido e quente da área da fralda constitui fator predisponente para essa infecção estafilocócica que é muito freqüente em recém-nascidos. É causada pelo Staphilococcus aureus tipo II, que produz toxina epidermolítica responsável pela separação das camadas superiores da epiderme. Apresenta-se como mácula eritematosa que se transforma em vesicopápula ou bolha purulenta, flácida, que se rompe facilmente, formando erosões. O diagnóstico é, em geral, clínico. Em casos especiais, pode ser feito exame bacterioscópico e culturas para a identificação do agente causal (Quadro 1).

\section{PREVENÇÃO E CUIDADOS}

Em bebês com dermatite da área das fraldas irritativa primária, o mais importante é prevenir. A remoção da oclusão ainda é a melhor forma de prevenção e tratamento. Para isso, recomenda-se um conjunto de medi- 


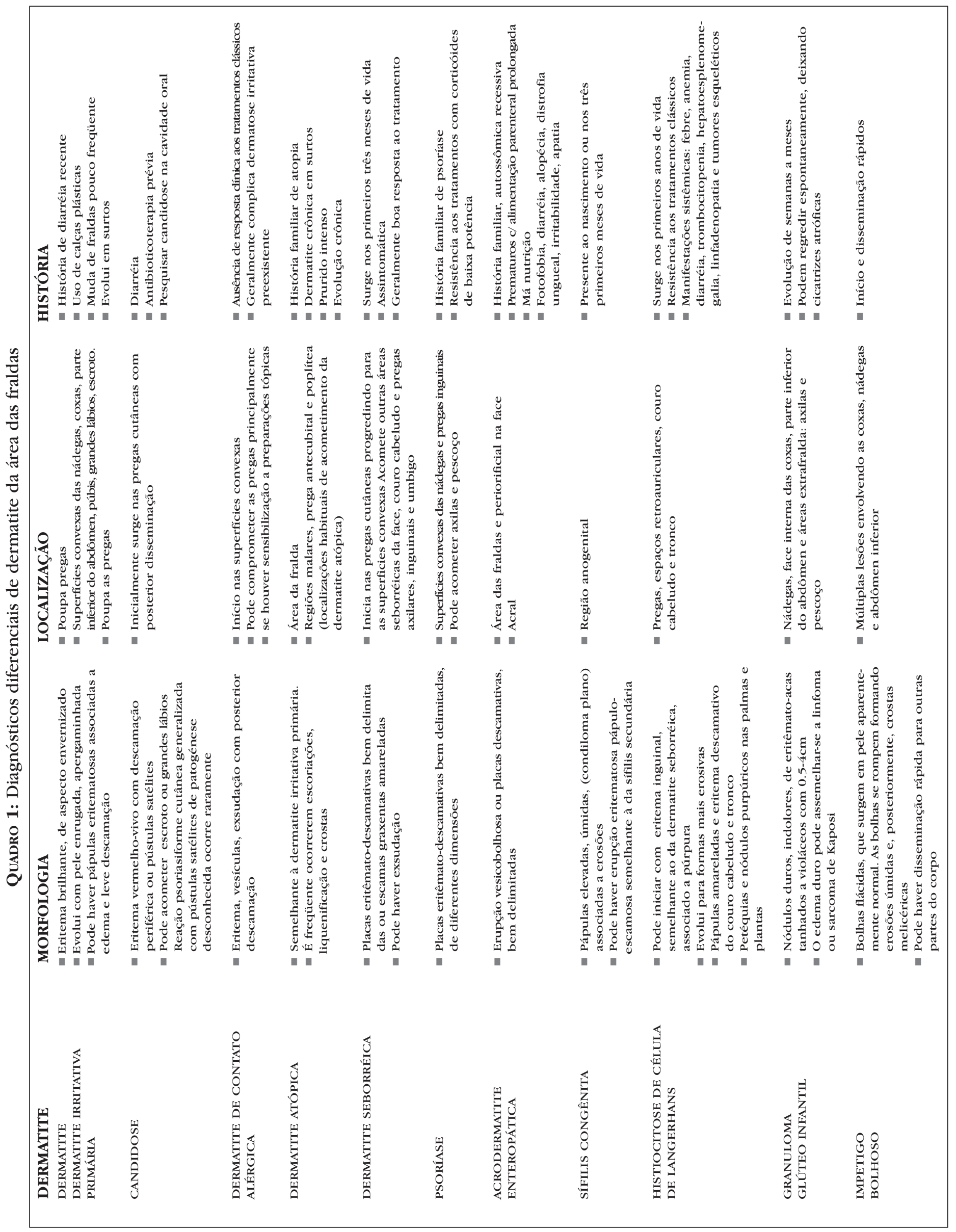


QuADro 2: Resumo do tratamento de dermatite da área da fralda

\section{GRAU DA DERMATITE}

Dermatite leve

Dermatite com eritema intenso

Dermatite com eritema intenso + pústulas

Dermatite com eritema intenso + pústulas

+ evidência de infecção secundária

Dermatites graves e prolongadas

Piora da dermatite prévia

\section{TRATAMENTO}

-trocas muito freqüentes de fraldas

-limpeza com agentes brandos e água morna

-cremes de barreira

-corticóide tópico de baixa potência (creme de hidrocortisona 1\% por 2 a 3 dias)

-suspeitar de infecção por Candida

-creme antifúngico, como nistatina ou miconazol $1 \%$, duas vezes ao dia por sete a 10 dias

antibioticoterapia tópica, como neomicina, gentamicina ou mupirocina a $2 \%$.

-alcatrões em pomada (controverso)

-pesquisar diagnósticos diferenciais, como dermatite atópica, dermatite seborréica, psoríase da área das fraldas e dermatite de contato das que têm como objetivos principais manter essa área seca. Para tanto é necessário evitar irritação e maceração, limitar a mistura e dispersão de urina e fezes, reduzir seu contato com a pele, o que ajuda a preservar a função de barreira cutânea e manter, sempre que possível, $\mathrm{pH}$ ácido. ${ }^{14-16}$ Procura-se dessa forma, eliminação ou minimização de todos os fatores implicados na etiopatogenia da doença. Assim existem cinco aspectos fundamentais na prevenção da dermatite da área das fraldas:

\section{Freqüência da troca de fraldas}

Devem-se trocar as fraldas sujas de urina com freqüência, a fim de que a capacidade de absorção não seja superada, evitando contato da urina com a pele. As fraldas com fezes precisam ser trocadas imediatamente. Em recém-nascidos, a troca deve ser horária, e nas outras crianças com três a quatro horas de intervalo. ${ }^{6}$

\section{Capacidade de absorção das fraldas}

Atualmente, a maioria das fraldas comercializadas contém material acrílico em gel superabsorvente, eficaz em manter a área da fralda seca e em meio ácido. Algumas fraldas mais modernas são compostas de substâncias capazes de seqüestrar líquido em até 80 vezes seu peso molecular, como é o caso do poliacrilato de sódio, que se transforma em gel (geleificação).${ }^{15-17}$ Apesar dessas especificações, a fralda descartável determina efeito oclusivo maior do que o das fraldas de pano, não eliminando o contato pele/fezes.13 Por isso não se deve estimular os pais a manter a mesma fralda por períodos mais longos.

\section{Fraldas descartáveis versus fraldas de pano}

As fraldas descartáveis superabsorventes são as que possuem maior capacidade de manter seca a área da fralda. ${ }^{17}$ Estudos anteriores compararam fraldas descartáveis superabsorventes com fraldas de pano e demonstraram que as primeiras produzem significativamente menos eritema, ${ }^{18-21}$ e menor grau de dermatite. Não foram descritas ainda reações alérgicas ao material absorvente contido nas fraldas descartáveis. ${ }^{17,22}$ Mesmo com o avanço nas técnicas de fabricação das fraldas descartáveis, há alguns autores que dão preferência às fraldas de pano pela menor oclusão que elas provocam. ${ }^{23}$ Para diminuir o calor local, as fraldas devem ser menores e mais anatômicas. ${ }^{21}$

\section{Controle de infecções}

A C.albicans contamina, freqüentemente, a dermatite da área da fralda, sendo a principal complicação da doença. A infecção por essa levedura deve ser considerada, pesquisada e tratada em dermatites com mais de três dias de evolução. ${ }^{24-26}$

\section{Higiene diária e preparações que devem ser evitadas}

A higiene da pele da área da fralda apenas com água morna e algodão, sem recorrer a sabonetes, é suficiente na limpeza diária da urina. Desse modo, é desnecessário lavar com sabão toda vez que a criança urinar, o que ocorre numerosas vezes ao dia, pois pode acarretar dermatite de contato pelo sabão. Para as fezes, sabonetes brandos são recomendados. O uso de lencinhos umedecidos pode ser útil somente em situações de locomoção. Deve-se sempre ter em mente que eles contêm sabões, e que, o contato continuado com a pele, pode lesar a barreira cutânea, provocando dermatite de contato. Seria adequado enxágue após o uso..$^{27-30}$

O uso rotineiro de preparações tópicas para prevenir dermatite da área das fraldas não é necessário para 
crianças com pele normal..$^{30}$ Os aditivos dessas preparações têm o potencial de causar sensibilização de contato, irritação e/ou toxicidade percutânea.

Para evitar a umidade excessiva da área das fraldas, minimizar as perdas transepidérmicas de água e diminuir a permeabilidade da pele, utilizam-se cremes de barreira ou pastas mais espessas e aderentes, à base de óxido de zinco, dióxido de titânio e amido ou cremes com dexpantenol. Esses produtos podem ajudar a prevenir o contato das fezes com a pele já danificada, pois aderem à epiderme. Não são facilmente removidos com água, mas sim com óleos e não devem ser retirados a cada muda de fralda para não irritar a pele. Sua utilização pode ser dispensada se as medidas de higiene e troca forem executadas com freqüência. Realmente, não se sabe se os aditivos presentes em alguns desses cremes de barreira (por exemplo, vitaminas) melhoram sua qualidade. Além disso, alguns aditivos, conservantes e aromatizantes presentes nos cremes protetores podem ter efeito de oclusão, levando, indesejavelmente, à dermatite da área das fraldas.

Algumas preparações devem ser evitadas: as que contêm ácido bórico pelos riscos de toxicidade, além de causar diarréia e eritrodermia; tratamentos caseiros, com clara de ovo e leite, por seu poder alergênico; produtos com corantes de anilina que podem levar ao envenenamento e meta-hemoglobinemia; desinfetantes e amaciantes, principalmente os que contenham hexaclorofeno ou pentaclorofenol pelo risco de encefalopatia vacuolar e taquicardia com acidose metabólica, respectivamente.

\section{TRATAMENTO}

O tratamento médico da dermatite da área das fraldas irritativa primária consiste em medidas simples, aplicadas de acordo com a gravidade e o tipo de dermatite (Quadro 2). ${ }^{27-30}$

Para dermatite instalada de grau leve, o mais importante consiste no aumento da frequência de trocas e na utilização de fraldas superabsorventes (nem todas as marcas o são). Devem-se evitar, também, fraldas de pano, que permitem maior contato da urina e fezes com a pele e exigem medidas de eliminação de microorganismos (lavagem com sabão e fervura). É recomendável, na limpeza da área da fralda, primeiro usar algodão embebido em óleo (mineral ou vegetal), para remover o óxido de zinco e resíduos de fezes aderidos à pele, e só depois proceder à lavagem com sabonetes pouco agressivos.
Deve-se lavar em água corrente para melhor remoção de resíduos. Uma possibilidade é o uso até três vezes ao dia de compressas frias com solução de Burow 1:30, que confere efeito calmante, antisséptico e secativo. ${ }^{13}$

Se o eritema persistir, pode-se associar corticóide tópico de baixa potência, como hidrocortisona a $1 \%$, no máximo duas vezes ao dia por dois a sete dias a fim de aliviar a inflamação. Corticóide fluorado, de potência mais elevada está contra-indicado pelo risco inerente de atrofia e de estrias, além de o efeito oclusivo da fralda aumentar sua potência. Deve-se ficar atento também aos efeitos colaterais sistêmicos dessa substância, como síndrome de Cushing e hipertensão intracraniana, que têm sido relatados mesmo com os de baixa potência, pois, além da oclusão, a superfície corporal dessa área é significativa. ${ }^{24}$

Se a dermatite não melhora, mantendo eritema intenso e pústulas, a suspeita principal é de infecção por Candida. Nesse caso, se poderá adicionar duas vezes ao dia por sete a 15 dias creme com ação antifúngica, como cetoconazol, nistatina a $100.000 \mathrm{U} / \mathrm{g}$ ou nitrato de miconazol $1 \%$ tópico, que são eficazes e seguros. ${ }^{24,13} \mathrm{O}$ corticóide pode ser revezado com o antifúngico, aplicando-os antes do creme barreira. Embora careça de evidência, muitos casos graves e prolongados beneficiam-se do uso de nistatina oral, quatro vezes ao dia por 14 dias. Fluconazol pode ser indicado na dose permitida para a idade, embora na experiência das autoras seu uso seja excepcional.

Em dermatites prolongadas, também podem ser utilizados alcatrões em pomada, o que, entretanto, em alguns países está contra-indicado pelos riscos de carcinogênese.

Infecções bacterianas são mais raras com as fraldas descartáveis do que eram com as de pano e podem ser tratadas com neomicina, gentamicina ou mupirocina tópicas a $2 \%$. Esta última, entretanto, não deve ser utilizada em mais de $20 \%$ da superfície corporal pelo risco de nefrotoxicidade. Os antibióticos orais podem agravar o quadro por afetar a flora intestinal. ${ }^{13}$

Se, apesar do tratamento correto, ocorrer piora da dermatite prévia, devem-se sempre pesquisar os diagnósticos diferenciais já citados, como dermatite atópica, dermatite seborréica, psoríase da área das fraldas e dermatite de contato. O acompanhamento das crianças com dermatite da área das fraldas deve ser regular, alem de se dispensar atenção especial nos períodos diarréicos ou de uso de antibiótico sistêmico. 


\section{REFERÊNCIAS}

1. Janssen M, Cerqueira AMM, Oliveira JC, Azulay RD. Dermatite das fraldas. An Bras Dermatol. 1993;68:85-6.

2. Jacquet L. Traitae des maladies de l'enfance. In: Grancher J, Comby J, Marfan AB, eds. Paris: Masson\&Co; 1897. p.714.

3. Jordan WE, Lawson KD, Berg RW, Franxman JJ, Marrer AM. Diaper dermatitis: frequency and severety among a gener al infant population. Pediatr Dermatol. 1986;3:198-207.

4. Leyden JJ. Diaper dermatitis. Dermatol Clin. 1986;4:23-8.

5. Nelson WE. Tratado de Pediatria. 11 ed. Rio de Janeiro: Ed. Interamericana; 1983. vol. 2. p. 1781.

6. Wolf R, Wolf D, Tuzun B, Tuzun Y. Diaper dermatitis. Clin Dermatol. 2000;18:657-60.

7. Zimmerer R, Lawson KD, Calvert CJ. The effects of wear ing diapers on skin. Pediatr Dermatol. 1986;3:95-101.

8. Concannon P, Gisoldi E, Phillips S, Grossman R. Diaper dermatitis: a therapeutic dilemma. Results of a doubleblind placebo controlled trail of miconazole nitrate $0,25 \%$. Pediatr Dermatol. 2001;18:149-55.

9. Cohen BA. Dermatologia neonatal. Dermatologia pediátri ca. São Paulo: Editora Manole; 2000. p.28-9.

10. Rodriguez-Poblador J, Gonzalez-Castro U, HerranzMartinez S, Luelmo-Aguilar J. Jacquet erosive diaper dermatitis after surgery for Hirschsprung disease. Pediatr Dermatol. 1998;15:46-7.

11. Thiboutot DM, Beckford A, Mart CR, Sexton M, Maloney ME. Cytomegalovirus diaper dermatitis. Arch Dermatol. 1991;127:396-8.

12. Atherton DJ. The neonate. In: Rook A, Wilkinson DS, Ebling FJG. Textbook of dermatology. London: Blackwell Science; 1998. p.468-72.

13. Virgili A, Corazza M, Califano A. Diaper dermatitis in an adult. A case of erythema papuloerosive of Sevestre and Jacquet. J Reprod Med. 1998;43:949-51.

14. Juez JL, Gimier LP. Ciencia cosmética bases fisiológicas y critérios prácticos. Madrid: Consejo General de Colegios Oficiales Farmacéuticos; 1995.212.

15. Eichenfield LF, Hardaway CA. Neonatal dermatology. Curr Opin Pediatr. 1999; 11:471-4.

16. Rocha N, Horta M, Selores M. Terapêutica tópica em der matologia pediátrica. Nascer Crescer. 2004;13:215-25.

17. Orange AP. Management of napkin dermatitis. In: Harper J, Orange A, Prose N, eds. Textbook of Pediatric Dermatology. Oxford: Blackwell Sciences; 2000. p.153.

18. Campbell RI, Seymour JL, Stone LC, Milligan MC. Clinical studies with disposable diapers containing absorbent gelling materials: evaluation of effects on infant skin con dition. J Am Acad Dermatol. 1987;17:978-87.
19. Seymour JL, Keswick BJ, Hanifin JM, Jordan WP, Milligan MC. Clinical effects of diaper types on the skin of normal infants and infants with atopic dermatitis. J Am Acad Dermatol. 1987; 17:988-97.

20. Wilson PA, Dallas MJ. Diaper performance: maintenance of healthy skin. Pediatr Dermatol. 1990;7:179-84.

21. Orange AP, de Waard-Van der Spek FB. Comparison of cloth and superabsorvent paper diapers for preventing diaper dermatitis. Eur J Pediatr Dermatol. 1991;1:225-32.

22. Runeman B. Skin interaction with absorbent hygiene products. Clin Dermatol. 2008;26:45-51.

23. Wong DL, Brantly D, Clutter LB, De Simone D, Lammert D, Nix K. Diapering choices: a critical review of the issues. Pediatr Nurs. 1992;18:41-54.

24. Casamitjana M, López Martínez R, Ruiz Maldonado R, Sánchez Nieto D, García E. Bacteriological and mycologi cal study of diaper dermatitis. Rev Latamer Microbiol. 1982;24:211-4.

25. Caputo RV. Fungal infections in children. Dermatol Clin. 1986;4:137-49.

26. Dixon PN, Warin RP, English MP. Role of candida albicans infection in napkin rashes. Br Med J. 1969;5:23-7.

27. Scheinfeld N. Diaper dermatitis: a review and brief survey $f$ eruptions of the diaper area. Am J Clin Dermatol. 2005;6:273-81.

28. Prasad HR, Srivastava P, Verma KK. Diaper dermatitis--an overview. Indian J Pediatr. 2003;70:635-7.

29. Henry F, Thirion L, Piérard-Franchimont C, Letawe C, Piérard GE. How I treat...diaper dermatitis. Rev Med Liege. 2006;61:212-6.

30. Adam R. Skin care of the diaper area. Pediatr Dermatol. 2008;25:427-33.

\footnotetext{
ENDEREÇO PARA CORRESPONDÊNCIA / MAILING ADDRESS: Juliana Dumêt Fernandes Av. Dr. Enéas de Carvalbo Aguiar, 255, $3^{\circ}$ andar, sala 3070 - Cerqueira César 05403001 - São Paulo - SP

Tel./fax: (11) 3069-6000

E-mail:jdumet@gmail.com
} 